ISSN 00156043

\title{
DOCUMENTO
}

\section{Palabras de Manuel Segura Morales S. I. en su inves- tidura como doctor honoris causa}

El profesor Manuel Segura Morales S.I. recibió el doctorado "honoris causa" por la Universidad de la Laguna el 21 de mayo de 2012. La Revista de Fomento Social se honra al poder publicar la versión íntegra de las Palabras pronunciadas por el nuevo doctor en aquel acto.

Manuel Segura Morales nació en Granada el 25 de octubre de 1928 y en 1945 entró en la Compañía de Jesús (Provincia Bética), realizando parte de su formación académica en Inglaterra y recibiendo la ordenación sacerdotal en 1957. Vivió diez años en América latina, entre el Paraguay ajo la dictadura de Stroessner y Chile durante el Gobierno de Salvador Allende, siendo en ambos países superior mayor de los jesuitas. Fue también Rector de las Escuelas Profesionales de la Sagrada Familia de Andalucía (SAFA), aunque la mayor parte de su vida ha transcurrido en Tenerife (Canarias), donde ha sido profesor en la Universidad de La Laguna. Actualmente está en la residencia jesuita de Córdoba.

Su preocupación por la infancia y la adolescencia le llevó a crear en los años 80 el programa denominado genéricamente de "Competencia social", que se ha extendido por toda España y algunos países de América Latina. Este programa tiene una versión para trabajar escolarmente en educación primaria y secundaria y otra para intervenir con población en riesgo social. El objetivo principal del programa es la mejora de las relaciones interpersonales y que ésta redunde en el desarrollo personal; por ello el programa para adolescentes se titula precisamente "Ser persona y relacionarse".

El programa busca enseñar a convivir, dotando a las personas de estrategias de afrontamiento en situaciones interpersonales complejas, aprendiendo a autorregular las emociones y los sentimientos para favorecer la relación teniendo en cuenta las emociones y sentimientos de la otra persona, potenciando un desarrollo moral y en valores de acuerdo a la edad y permitiendo que las relaciones se desarrollen pacíficamente y desde la asertividad. Segura ha dedicado una atención preferente a aquellos centros escolares que tenían alumnado con grandes dificultades; conflictividad en las aulas, altos niveles de desestructuración familiar (drogodependencias, delincuencia, paro) o bajo rendimiento académico, etc. Su trabajo se ha difundido por diferentes lugares y ha despertado especial interés en Cataluña, el mismo aprecio que posteriormente se ha 
extendido por otras regiones, dando lugar a acciones formativas para docentes, equipos de orientación, equipos directivos del sector público como de iniciativa social, así como sindicatos, escuelas de madres y padres o centros de formación del profesorado.

Hoy mi primera palabra no puede ser otra que igracias! Gracias a todos los compañeros que han propuesto y han promovido este doctorado honoris causa para mí. Gracias a la Universidad y a sus autoridades que han aprobado este honor tan grande que me llena de alegría al fin de mi vida y me hace sentir de nuevo joven, en edad de estudiar, de seguir estudiando.

Cuando el Rey Alfonso XIII concedió la Medalla de Oro a don Miguel de Unamuno, éste, en su discurso, dijo que agradecía que por fin le hubieran concedido un honor tan merecido. Cuando minutos después tomaban una copa de vino, el Rey le dijo sonriente: " $\mathrm{i} H$ Hombre! Me ha sorprendido y hecho gracia que digas que este honor es para ti tan merecido; todos aquellos a quienes se lo hemos concedido antes, absolutamente todos, lo primero que dijeron es que era totalmente inmerecido". A lo cual replicó rápido don Miguel: "Y tenían razón, ninguno se lo merecía". Pues sin dudarlo un instante, hoy me encuentro entre el grupo citado por Unamuno: no me merezco este honor. Y por eso, se lo agradezco a ustedes doblemente.

En Granada, donde nací, tuve el honor de tener como padrino de bautismo a don Manuel de Falla, que siempre me instruyó en la fe y me trató con afecto hasta mis once años, en 1939, cuando se fue definitivamente a Argentina, apenado por los fusilamientos semanales que él oía desde su casa en la Antequeruela, en la Alhambra. También conocí a Federico García Lorca y recuerdo su vitalidad, su alegría, el entusiasmo con que improvisaba una obra de teatro en la que todos los hermanos, nueve en total, teníamos un papel inventado por él.

Mi padre fue catedrático de Historia del Derecho, primero en Salamanca, donde Unamuno era Rector y luego en Granada. De él, de mi padre, fue del primero que aprendí que enseñar a otros es una gloria, una vocación maravillosa.

Lo mismo me inculcaron en todo momento los jesuitas, desde el primer momento que entré en esta orden religiosa, en 1945. Precisamente mi inquietud por enseñar a delincuentes y marginados se despertó por unos documentos importantes de la Compañía de Jesús, que animaban a los jesuitas del mundo entero a dar la misma importancia al trabajo por la justicia que al trabajo por la fe. Esa inquietud se acentuó fuertemente durante los diez años que pasé en América Latina, viendo a los niños que dormían entre cartones, en las calles de Brasil, de Paraguay o Chile y que recogían flores de la basura para ofrecerlas a quienes pasaban por la calle y obtener una propina que les permitiera vivir. 
Allí en América, en la Universidad de Asunción, conseguí mi tercera Licenciatura, esta vez en Pedagogía, y me doctoré en Educación

Cuando volví a España, en 1972, y tuve la inmensa suerte de ser destinado a Tenerife, decidí trabajar en una nueva tesis, en vez de iniciar el trámite de convalidación del doctorado americano. Así, al mismo tiempo que daba clases en la Escuela de Magisterio de la Iglesia, en Santa Cruz, me metí de lleno en el estudio de la delincuencia juvenil, bajo la dirección de un profesor de la Universidad de Valencia, Francisco Rivas, experto en ese tema (aquí en La Laguna no había entonces ningún estudioso de la delincuencia). Así obtuve en la Universidad de Valencia mi segundo doctorado, con la tesis "Tratamientos eficaces de delincuentes juveniles", que fue publicada de inmediato por el Ministerio de Justicia y repartida por los Centros de Menores y las Prisiones de toda España.

Poco después la Escuela de Magisterio de la Iglesia fue definitivamente incorporada a la Universidad y desde entonces sólo existió un único Centro, la Escuela de Magisterio de La Laguna. Enseñando ya en dicho Centro, empecé a trabajar en un proyecto educativo destinado a delincuentes. Trabajé junto con el profesor Vicente Garrido, de la Universidad de Valencia, y ambos bajo la dirección del profesor Robert Ross, de la Universidad de Ottawa, en Canadá, uno de los grandes expertos mundiales en delincuencia (que por cierto fue invitado en tres ocasiones por esta Universidad y compartió su sabiduría con nosotros en La Laguna). Elaboramos un Programa que poco después ofrecimos a la cárcel de Tenerife, entonces en la avenida Pérez de Armas, de Santa Cruz, y al Centro de Menores, entonces en la Curva de Gracia, bajo la responsabilidad de los Terciarios Capuchinos.

El Programa fue un éxito inmediato y pronto se interesaron por él otros centros penitenciarios y otros centros de Menores en varias Provincias de España.

Fue entonces cuando algunos profesores de Primaria y Secundaria en Tenerife, que conocieron el Programa, propusieron si no sería posible modificarlo, de manera que pasara a ser preventivo en vez de curativo, y así se pudiera aplicar a los "alumnos difíciles" que todos ellos tenían, en número pequeño pero significativo, en sus clases. Atendiendo esa petición tan justa, trabajé durante un año, en reuniones semanales, con expertos en Educación Compensatoria y analicé el Programa a fondo en uno de los Cursos de Doctorado de esta Universidad. Conté siempre con el apoyo de los compañeros de Departamento y, más tarde, con el aliento del Consejo Escolar de Canarias. Así pudimos redactar ya un Programa completo, para alumnos normales, en dos versiones: una para Primaria y otra para Secundaria. 
Con la ayuda entusiasta de muchos profesores no universitarios, que enriquecieron el Programa con sus sugerencias, empezamos a presentarlo por las siete Islas Canarias, con la valiosa ayuda, primero de Juani Mesa Licenciada en Psicología y después la de Margarita Arcas, profesora de Primaria, a quien la Consejería de Educación generosamente destinó a colaborar en la difusión e implantación del Programa. Fuimos a todos los Centros que lo pidieron y explicamos el Programa en cursillos de doce horas a todo el claustro. Dimos también cursos de esa misma duración en todos los CEP que nos lo pidieron. Así pudimos preparar a un buen número de profesores en todas las Islas, para impartir ellos el Programa en sus clases, a sus alumnos.

Entonces la Consejería de Educación de Canarias tuvo un nuevo gesto de generosidad con nosotros e imprimió, como libros muy atractivos, los materiales de Primaria y Secundaria, que hasta entonces habíamos repartido a los profesores en fotocopias. Fue un paso importante, un espaldarazo al Programa, que coincidió con una iniciativa del CEP de La Laguna para grabar un video de dos horas en el que yo explicaba todo el Programa. Lo grabamos en Radio Nacional, en Santa Cruz, con una excelente calidad técnica. En esas dos horas, yo presentaba, con todo detalle, las tres partes fundamentales del Programa: lo cognitivo, lo emocional y lo referente a los valores.

Algunos CEP de la Península empezaron a interesarse por ese Programa. Recibí invitaciones de Sevilla, de Madrid, de Málaga, de Oviedo y fui a cada uno de esos sitios a presentar el Programa en un cursillo de doce horas, tres tardes, cuatro horas cada tarde. También el Secretariado de Educación de Comisiones Obreras me invitó a exponer el Programa, en doce horas, a representantes de todas las Provincias de España, en Madrid. Para cada uno de esos viajes, era necesario pedir permiso del Rector de esta Universidad, en la que yo era profesor, permiso que siempre fue amablemente concedido.

Nuestro principal escenario seguían siendo las Islas Canarias. Pero en medio de estos trabajos y de las clases en la Escuela de Magisterio de esta Universidad, un día ocurrió algo muy importante para el futuro del Programa y de su difusión por toda la Península: recibí una llamada de Barcelona, del señor Pere Led, Director General de Formación del Profesorado en la Generalitat de Cataluña. Me dijo por teléfono (todavía lo recuerdo): "me han hablado varias veces muy elogiosamente de su Programa. La primera vez no hice caso; la segunda vez no hice caso; pero la tercera vez, hace muy pocos días, me han hablado con grandes ponderaciones unos educadores catalanes muy relevantes, que acaban de asistir a un congreso en Las Palmas y allí han tenido ocasión de conocer su Programa. Así que ahora 
sí estoy interesado; pero como buen catalán no compro nada sin verlo antes. De modo que dígame qué cursos tiene pendientes en las próximas semanas - ya faltaba poco para fin de curso - y por favor permítame asistir a uno de ellos". Le dije que el próximo era en Icod de los Vinos y respondió rápido que asistiría con gusto, pero que no dijera a los participantes que él era una autoridad, sino que lo presentara como un profesor catalán de Secundaria, interesado en el Programa. Así lo hicimos: él participó con sencillez, como un profesor más, y quedó entusiasmado con el Programa.

Me invitó a dar mi curso de doce horas en Barcelona a principios de noviembre. Como participantes invitó a los Directores y Jefes de Estudio de los Institutos más conflictivos de Barcelona y Gerona, unas treinta personas en total. Lo hicieron muy activamente, participando con mucho interés. Al terminar los tres días, es decir las doce horas de cursillo, el Director del Instituto más conflictivo de Barcelona, en El Raval, me dijo delante de todos: "El Programa me ha interesado mucho y le veo grandes posibilidades. Pero no creo en panaceas y me quedan dudas de si esta será la solución definitiva para la violencia, la agresividad y el pasotismo de los alumnos. Lo que le prometo es que lo vamos a dar, el Jefe de Estudios y yo, una vez por semana, como usted recomienda, a los cuatro cursos más conflictivos del Centro. Empezaremos de inmediato, ahora en Noviembre, y seguiremos hasta Junio. Me comprometo a seguir hasta el final, aunque vea que no me gusta, aunque me aburra y se aburran los alumnos, aunque me parezca que estamos perdiendo el tiempo. Llegaremos hasta el final, y en Junio, cuando nos volvamos a ver, le diré si el Programa sirve o no sirve, si seguiremos impartiéndolo a los alumnos o lo dejamos para siempre".

Me pareció una actitud responsable y justa y así se lo dije.

Cuando nos volvimos a reunir, ya en Junio, él habló el primero, para decirme delante de todos: "He dado el Programa completo a dos cursos y el Jefe de Estudios a otros dos. Han cambiado radicalmente los alumnos, ha cambiado el profesorado, ha cambiado el instituto entero. Así que desde ahora lo daremos todos los años, a todos los cursos de secundaria, aunque tuviéramos que quitarle tiempo a las Matemáticas". Así lo ha hecho durante años y ahora, como Inspector, cuida mucho de que se haga en los centros que dependen de él y recomienda a los otros Inspectores que hagan lo mismo. Desde el principio, todos los profesores de Cataluña cuentan con todo el material, traducido al catalán por la Consejería de Educación y también cuentan con frecuentes cursos, ya no necesariamente impartidos por mí, pues hay 40 profesores de secundaria que los realizan con sus compañeros, con suma competencia y lo mismo hacen 27 profesores de primaria 
con sus compañeros. El resultado es que más de 9.000 profesores catalanes han hecho los cursos y conocen el Programa y un tanto por ciento muy elevado de ellos lo está impartiendo a sus alumnos. El sistema para impartir los cursos es muy sencillo: se descuentan 100 horas de tiempo lectivo, al año, a los profesores que los darán y ellos toman la responsabilidad de dar cinco cursillos de veinte horas a sus compañeros en ese año, por las tardes, fuera de horario lectivo. Los cursos son de veinte horas, no de doce, porque en ellos hacen prácticas sobre los temas del Programa, hacen dilemas morales y preparan a los compañeros que asisten a esos cursillos para impartir el Programa a los alumnos con toda seguridad y competencia.

Pronto Valencia tuvo noticias de los buenos resultados en Cataluña y siguió los mismos pasos. Hasta ahora, han asistido a los cursos y conocen bien el Programa más de 4.000 profesores de la Comunidad Valenciana.

Y de ahí a Granada, Santander, Málaga, Bilbao y casi todas las capitales de provincia. Haciendo la lista de todas ellas, he llegado a la conclusión de que es más fácil decir en qué ciudades españolas "no" hemos dado el curso. Son Huelva, Lugo, Orense, Teruel y Melilla. En todas las demás, incluidas Ceuta, Palma de Mallorca, Mahón, San Antonio de Ibiza hemos dado a conocer el Programa y también en muchos pueblos y ciudades, por ejemplo: Marbella, Fuengirola, Zafra, Mérida, Priego, Montilla, Dos Hermanas, Osuna, Motril, Almuñécar, Atarfe, Pozoblanco, Peñarroya, El Escorial, Santurce, Sagunto, etc.

Además de todo eso, he tenido ocasión de explicar el Programa en Chile, en Paraguay, en Uruguay, en Colombia, en Perú, en Ecuador, en México y este año, en junio, lo llevaré a Venezuela, donde varios colegios y dos universidades quieren hacer de este Programa el centro de la formación humana de sus alumnos, para el próximo curso académico, 2012-2013.

Todos los informes y evaluaciones de los profesores que están usando el Programa en sus clases, son positivos. Además ya se han presentado tres tesis doctorales sobre la eficacia de este Programa. La primera fue en la Universidad de Valencia, donde la doctora Dolores Martínez Francés estudió los resultados muy positivos del Programa con un curso de primaria. Las otras dos tesis se han presentado en La Laguna. La doctora María Suárez escribió una muy interesante tesis sobre la eficacia del Programa con niños hipoacúsicos; de cincuenta variables que midió antes y después de impartir el programa (a principio del curso lectivo y siete meses después), los alumnos, en esos siete meses, habían progresado en 49 . La variable que curiosamente no había mejorado era la opinión general del conjunto de los 
compañeros sobre cada alumno: después de reconocer que ya no peleaba como antes, que ya no insultaba como antes, que ya no gritaba como antes, etc., al decir cómo lo calificarían, decían lo mismo que antes de realizar el curso: "un gamberro", "un caprichoso", etc. Eso confirma el dicho popular de "cría fama y échate a dormir".

La tercera tesis, también presentada en La Laguna, por la doctora Juani Mesa, bajo la dirección de la profesora María Dolores García Hernández, versó sobre los resultados muy positivos en secundaria, tanto con alumnos agresivos como con los tímidos o inhibidos. Hizo la tesis en Barcelona y estudió una muestra de 640 alumnos catalanes.

En las cárceles y centros de menores, el porcentaje positivo de los resultados no puede ser, naturalmente, como el conseguido con alumnos normales. Pero los cambios radicales de vida, la nueva inserción de ellos en la sociedad y en el mundo del trabajo, son de las experiencias más gratificantes que he vivido como educador. Cuando personas generalmente criadas en un mundo muy agresivo y muchas veces sin familia, o con una familia de influencia totalmente negativa, y convertidos después en delincuentes habituales durante años, empiezan a usar su cabeza para pensar, aprenden a conocer y controlar sus emociones y acaban por aceptar sinceramente en su vida los grandes valores morales, el cambio que se opera es espectacular. Como me decía un preso de la cárcel Tenerife 2, ahora convertido en trabajador honrado y padre de familia: "Don Manuel, es que antes de conocer este Programa, yo tenía la cabeza sin estrenar".

En su último libro Flourish (traducida al español como La vida que florece) Martin Seligman contradice la célebre frase de Jean Paul Sartre el infierno son los otros, diciendo que actualmente hay acuerdo unánime y total, tanto entre los filósofos como entre los psicólogos, sobre el hecho de que la verdadera alegría y felicidad nos viene solamente de los otros, del amor y amistad de los otros. Y que ser persona, consiste precisamente en relacionarse con los demás. Confirma Seligman lo que ya dijo Erich Fromm hace años: que el deseo más profundo del ser humano es relacionarse y el miedo más terrible del ser humano es a encontrarse solo, sin nadie a quien querer y sin nadie que le quiera. Decía Fromm que quien se encuentra así, aislado de todos, está al borde del suicidio o de graves enfermedades personales.

Permítaseme aquí introducir una anécdota curiosa vivida por mí con los presos de la cárcel. Uno de 27 años, bien parecido, me dijo con mucho énfasis, que él no tenía a nadie; ni padres, porque su madre era prostituta en el Sur de Tenerife y 
por tanto nunca había conocido a su padre; ni madre, porque nunca se entendió con ella, de modo que ella terminó por echarle de su casa a la calle, cuando él tenía 12 años de edad. Tampoco tuvo amigos, ni amigas (seguramente repelidos por su carácter amargo y egoísta). Acordándome de la afirmación de Fromm, que quien no tiene nadie que le quiera y nadie a quien querer, está al borde del suicidio, le pregunté si no había pensado nunca en suicidarse. Muchas veces, me respondió, ¿pero sabe usted por qué no me he suicidado? En mi larga vida he oído a varias personas decirme que se matarían, pero que no lo hacían por su mujer, por su marido, por sus hijos, por sus padres o porque eran creyentes y sabían que Dios no aprobaba el suicidio. Esperando una respuesta de ese estilo, le pregunté: ¿por qué? ¿ ¿por qué no te has suicidado? Y la sorprendente respuesta fue: para no darles ese gusto a los que no me pueden ver. Es decir, que no se suicidaba por fastidiar. Algo increíble.

Con esto que llevamos dicho, queda claro que si para nosotros cualquier plan de educación debe consistir básicamente en formar personas, debemos recordar con la misma claridad que formar personas es lo mismo que enseñarles a relacionarse con los demás. En eso hay acuerdo prácticamente unánime hoy día entre los expertos en educación. Donde empiezan las diferencias es al determinar cuáles son los factores necesarios para conseguir esa relación sana, amistosa, con los demás. Se puede decir que en los últimos años ha habido "Cuatro oleadas" poderosas, al tratar de establecer los elementos necesarios para formar personas.

La primera oleada, cronológicamente, fue la enseñanza de Habilidades Sociales. Se pensó que, sin necesidad de cambiar profundamente a la persona, se le podía enseñar a relacionarse con los demás de manera asertiva, no inhibida y no agresiva. Actualmente, la opinión más extendida es que las habilidades sociales son el final del proceso, no el comienzo. Se puede y se debe enseñar habilidades sociales a personas que ya sepan pensar, que ya controlen sus emociones, que ya acepten en su vida los principales valores morales. Esas habilidades serían un barniz último. Aplicar ese barniz sobre una madera sana y fuerte, embellece notablemente esa madera. Aplicarlo sobre madera podrida, tiene una falsa apariencia de belleza, pero cuando nos apoyamos sobre esa madera, se parte, no resiste porque está podrida.

Descartando esta primera oleada, optimista pero poco sólida, han venido más recientemente las otras tres: la oleada de enseñar a pensar, la de enseñar a conocer y controlar las emociones y la de ayudar a reconocer los grandes valores morales. 


\section{La primera oleada fue que hay que enseñar a pensar}

El eslogan de estos autores es muy claro y tajante: La escuela del siglo XXI será la escuela de enseñar a pensar. Creen que ya pasó el tiempo de insistir en los contenidos, que ahora pueden adquirirse por otros muchos canales, fuera de la escuela. Con este presupuesto de la prioridad absoluta del pensamiento, se han elaborado magníficos programas para enseñar a pensar. Por ejemplo el programa llamado "Filosofía en el aula" de Matthew Lipman, que entre nosotros sigue teniendo vigencia, sobre todo en Valencia y en Madrid. Otro ejemplo de método para enseñar a pensar es el "Programa de enriquecimiento instrumental", PEl, de Feuerstein, Israel, utilizado en muchas provincias españolas, debido en gran parte al esfuerzo de los Hermanos de la Salle, que optaron por ese método para sus colegios. Otro ejemplo, lleno de originalidad y muy ameno y divertido es el CORT, de Edward De Bono, donde se enseña el "Pensamiento lateral y la lógica fluida". También hay que incluir en esta "oleada" de enseñar a pensar, la original y muy seria "Teoría de las inteligencias múltiples", de Howard Gardner, Profesor en Harvard y recientemente galardonado con el Premio Príncipe de Asturias.

En esta misma línea de enseñar a pensar, se han publicado varios libros, de mucho éxito, El mundo de Sofía de J. Gaarder y Más Platón y menos prozac y Pregúntale a Platón, ambos de Lou Marinoff.

En seguida concretaremos cuáles son los pensamientos específicos que hay que enseñar a los alumnos. Decir sólo que hay que enseñar a pensar, queda muy indefinido y se presta a cualquier conclusión.

No sólo los autores citados: todos los expertos están de acuerdo en que el primer substrato de toda educación completa, de toda educación que quiera formar personas, es enseñar a pensar, a usar el cerebro.

Decía don Antonio Machado que De diez cabezas, nueve / embisten y una piensa. Tanto Fernando Savater y Howard Gardner, como Daniel Goleman explican que nuestro cerebro humano tiene dos partes bien diferenciadas: la posterior $y$ más antigua, que tenemos en común con los animales mamíferos, a la que llaman paleo-córtex, y la anterior, los lóbulos frontales, la frente, la parte más reciente en el proceso de evolución, a la que llaman neo-córtex. Pues bien, hay muchos jóvenes que sólo usan el paleo-córtex, el cerebro animal, no el humano. Ese cerebro animal, enfrentado a cualquier dificultad, no tiene más que dos salidas: ataque o huída. Un animal, si encuentra a otro que le impide sus propósitos, en situaciones de hambre o de celo, ataca al otro, si el otro es más débil, o huye si el otro es más 
fuerte. No hay diálogo ni negociación posible. Y un joven que sólo conoce y utiliza el paleo-córtex, da por supuesto, como un dogma indiscutible, que sólo se puede huir o atacar. Pero como la huída es cobardía y fracaso, sólo queda el ataque, si uno quiere triunfar en esta selva terrible del mundo actual. Por eso los más agresivos se consideran triunfadores y se hacen líderes, tienen a gala grabar en sus teléfonos móviles las palizas que les dan a otros, para luego enseñar esas grabaciones y que todos les admiren y les teman. Así muchas veces, en nuestros colegios e institutos, en nuestros barrios y nuestras calles, se hacen líderes los que están más atrasados en la evolución, los que sólo usan el cerebro animal, los que están más cerca de los primates. Es un caso curioso, que tiene su explicación en que no sólo ellos, sino también sus compañeros desconocen el neo-córtex y dan por supuesto que sólo son posibles la timidez o la agresividad. Y no ocurre sólo entre los jóvenes, sino que también es la actitud de los adultos que cada día ponen bombas en Afganistán o en Siria, o de los políticos que no dialogan, sino que sólo se enfrentan.

La solución no es ponernos nosotros más violentos que los violentos, sino enseñarles a usar el neo-córtex, la frente, para pensar y no para embestir. Enseñarles a dialogar y a resolver los problemas con eficacia y con justicia. Estas dos palabras, "eficacia" y "justicia", son ideas-clave para todo lo que queremos conseguir con una educación recta. Eficacia y justicia son lo contrario de huída o cobardía y son también lo contrario de agresividad o violencia. Pero ¿̇ómo conseguirlas?

\section{Enseñando a pensar}

Según Howard Gardner, la "inteligencia interpersonal" es la capacidad de relacionarse bien con los otros, de entenderlos y de hacerse entender. Dentro de las ocho inteligencias que Gardner enumera, ésta, la interpersonal, es la primera que nos interesa desarrollar si queremos educar socialmente, que es de lo que hablamos en estas páginas.

Pues bien, como prometíamos más arriba, vamos a mencionar los pensamientos específicos que hay que enseñar a quienes queramos que sepan pensar. Tanto la Psicología, como la Sociología han conseguido concretar los elementos cognitivos que forman esa inteligencia interpersonal: son la habilidad cognitiva de saber definir una situación humana interpersonal (problemática o no), la habilidad cognitiva de imaginar el mayor número de decisiones alternativas que puedan solucionar un problema, la habilidad cognitiva de prever las consecuencias de lo que se piensa hacer o decir, la habilidad cognitiva de ver las cosas desde la perspectiva del otro, es decir, ponerse en el lugar del otro, y la habilidad 
cognitiva de saber trazarse una meta, un objetivo, y saber encontrar los medios para llegar a esa meta. Desde hace mucho tiempo (ver por ejemplo R. Ross y E. FABIANO, 1985) se sabe que esas cinco habilidades le faltan, totalmente o en buena parte, a los delincuentes. Ni definen sus problemas, ni encuentran más soluciones que las violentas, ni piensan en las consecuencias de sus actos, ni se ponen en el lugar de las víctimas, ni tienen claro lo que quieren conseguir en la vida. Como ejemplo ilustrativo de lo que digo, recuerdo aquí lo ocurrido con el grupo de Menores de Tenerife. Un día propuse al grupo, quince muchachos entre los 14 y los 18 años, un problema concreto, para comprobar su capacidad de diagnosticar, como ejercicio del pensamiento causal, al mismo tiempo que usábamos el pensamiento alternativo. Les dije: vas en coche, con un adulto que tenga carné, y veis que un coche se ha salido de la carretera y ha volcado. Os detenéis, os acercáis y veis al conductor cabeza abajo, sujetado por el cinturón de seguridad y aparentemente muerto, ¿qué puede haberle pasado? Yo quería que me dijeran que se había dormido, que iba drogado, que se le reventó una rueda o se le partió la dirección, que le dio un infarto y estaba muerto, que resbaló con lluvia o con gravilla, que se distrajo con el teléfono móvil... Al menos, que me dijeran dos o tres de esas posibilidades. El líder del grupo (siempre hay un líder) levanta la mano y dice: que el tío iba borracho. Yo lo felicito, porque era una explicación posible y pregunto al grupo qué otra cosa podía haber pasado. El líder toma de nuevo la palabra y dice: no pregunte usted más, que es que iba borracho. Yo le replico sin enfadarme: ¿ Tú sabes lo que es la alcoholemia? Es el alcohol que uno tiene en la sangre después de haber bebido y se mide con un aparato especial en el que hay que soplar, o analizando la sangre. Al señor del coche le analizaron la sangre y tenía de alcoholemia 0,0; no había bebido alcohol en tres días: así que no digas que iba borracho. ¡Qué crees que podía haberle pasado?. Y me contesta: pues que iba borracho y el análisis está mal hecho.

No es este chico solo quien se aferra a una opinión preconcebida; hay muchos adultos que no saben distinguir entre hechos y opiniones y juzgan de todo, incluidas las intenciones de los otros, sin tener datos para ello, o en contra de los datos objetivos. Y una vez equivocados, actúan en consecuencia.

Pero la buena noticia, es que esas cinco habilidades cognitivas se pueden enseñar. El profesor DeBono inició esa enseñanza con su famoso curso CORT y yo mismo he publicado unos materiales para enseñar esas habilidades cognitivas a los alumnos de Primaria, a los de Secundaria y a los delincuentes. Se trata de dialogar con el grupo de alumnos sobre cómo no olvidar ningún factor importante de un problema o de una noticia; de buscar entre todos el mayor número posible de soluciones 
alternativas, para elegir la mejor; de jugar al juego de "¿qué pasaría si...?" para prever las consecuencias; de ponerse en el lugar de los otros, para intentar entender por qué hacen o dicen una cosa determinada $y$, por fin, de concretar lo que uno quiere conseguir, sus objetivos, y buscar los medios para alcanzarlos.

Además de esos materiales, se pueden usar también, de forma muy amena y eficaz, historietas cómicas o películas para enseñar las cinco habilidades cognitivas de las que venimos hablando. Lo explico. Casi todas, por no decir todas, las historietas y películas plantean muy al principio su problema central. Puede ser que a Zipi y Zape les pida una señora que le vendan un perrito que está jugando con ellos, pero que no es suyo. Puede ser que en un barco de vela, que navega por los mares del Sur, los marineros empiecen a tramar un motín contra el capitán. Puede ser que un hombre se enamore de una mujer casada, que también se siente atraída por él, pero que quiere ser, por encima de todo, fiel a su marido. En un "culebrón" televisivo puede ser que unos novios estén muy enamorados, pero que una chica más rica que la protagonista, trate de conquistar al novio y éste empiece a dudar, atraído por el dinero. Y así hasta el infinito: siempre hay un problema. El método para utilizar estos materiales es sencillo: se enseñan a los alumnos, en papel o en la pantalla, sólo las primeras escenas, hasta que esté claramente planteado el problema principal (puede haber subproblemas, que se pueden ignorar o se pueden discutir por separado, si hay tiempo). Se les pide que definan bien el problema, según los datos que da el dibujante de la historieta o el director de la película. Una vez se ha conseguido el acuerdo unánime en cuál es el problema y quién o quiénes lo tienen, se les pregunta qué soluciones alternativas se les ocurren, qué podría hacer el protagonista. A continuación, sin enseñar todavía nuevas viñetas o nuevas escenas de la película, se les pide que concreten las consecuencias, favorables y desfavorables, de cada una de las alternativas que se nos han ocurrido. De este modo, con unas pocas viñetas o unas pocas escenas, hemos ejercitado el llamado pensamiento causal (definir una situación, qué problema hay aquí), el pensamiento alternativo (cuántas salidas distintas hay) y el pensamiento consecuencial (qué pasaría si elegimos la salida $A$, qué si elegimos la $B$, o la $C$,). En este momento se entregan a los hijos o alumnos fotocopias del resto de la historieta o se proyecta el resto de la película. Y se pide a dos o tres (no más, para evitar el cansancio) que cuenten a todos la historia, pero en primera persona, como si ellos fueran uno de los personajes. Así se ejercita el llamado pensamiento de perspectiva, reflejando cada uno de los narradores lo que "su personaje" siente y sólo la parte de la historia que ese personaje sabe. Con otra historieta o con otra película, se muestra a los asistentes el principio y el final y se les pide que ejerciten el pensamiento medios-fin, para explicar cómo de ese planteamiento inicial se puede llegar a ese final, feliz o triste. El material para 
este trabajo, en historietas cómicas y en películas, es prácticamente inagotable. Sólo hay que prepararlo un poco.

\section{La segunda oleada fue la educación emocional}

Sólo un hombre bueno y además optimista, como Sócrates, puede creer que para ser bueno, para ser persona, basta con saber pensar rectamente. Y hoy día sigue habiendo gente buena y noble, que como Sócrates, piensan que cuando alguien procede mal es sólo por ignorancia. Pero esa afirmación sólo sería aceptable si en el término "ignorancia" incluimos no sólo los aspectos cognitivos, sino también los emocionales. Porque todos experimentamos con frecuencia, que muchas veces sabemos con toda claridad lo que deberíamos hacer y sin embargo hacemos lo contrario. Sencillamente porque nos ciega la ira, o nos ofusca el odio, o nos retrae el miedo, o nos frena la pereza, o nos desalienta la tristeza. Por eso, conocer las emociones es indispensable.

¿Qué deben saber los niños y los jóvenes acerca de las emociones? Cuanto más, mejor. Porque es un mundo maravilloso, complejísimo, que no tiene fin, como enseñó magistralmente Goleman en su libro de tanto éxito sobre la inteligencia emocional. Deben ir conociendo esas emociones, desde pequeños, desde los años de educación primaria, por medio de dibujos y fotos que muestren la diferencia entre una cara alegre, una enfadada, una triste, una asustada, una sorprendida, una avergonzada, una interesada, una aburrida. A continuación se les puede pedir que ellos representen sin palabras, sólo con gestos y con algún sonido, esas ocho emociones mencionadas. Luego se puede discutir con ellos qué situaciones son las que pueden producir en nosotros esas ocho emociones

Los alumnos de secundaria y bachillerato tienen, en la buena literatura y en las buenas películas, el mejor arsenal para aprender a conocer las emociones. Pero además pueden progresar mucho en poco tiempo, si ponemos en práctica con ellos alguno de los buenos programas surgidos últimamente para desarrollar la inteligencia emocional. Las actividades prácticas que se proponen en esos programas, se podrían resumir, más o menos como vamos a indicar a continuación, basándonos en la división en ocho familias que Goleman hace dentro del mundo de las emociones. Recordamos esas ocho familias y proponemos los ejercicios más útiles en cada una de ellas. 


\section{I.Alegría}

Los alumnos deberán saber definir con sus propias palabras, pero con claridad, qué es alegría, felicidad, satisfacción, júbilo, sentido del humor.

Y sus contrarias: tristeza, melancolía, nostalgia, depresión.

Igualmente, deberán ser capaces de determinar, con ejemplos de la vida diaria, qué acontecimientos y qué pensamientos son los que provocan esos sentimientos.

Respecto a la depresión, que se está convirtiendo en una verdadera plaga entre nosotros (el suicidio es ya la primera causa más frecuente de muerte entre los jóvenes, en España; antes era la segunda, después de los accidentes de carretera, pero actualmente ya es la primera), los alumnos deben aprender a distinguir entre depresión biológica (producida por un defecto genético que afecta a algún neurotransmisor, o impide la asimilación del litio), la fisiológica (no de nacimiento, sino derivada del consumo de drogas), la depresión producida por un problema antiguo no resuelto (ésta es la que preocupó a Freud), y la depresión producida por un problema actual (enfermedad grave, separación matrimonial, ruina económica, pérdida de un ser querido).

Naturalmente, en casos de depresión grave, se debe acudir a un profesional. Pero hay casos más benignos o unos inicios de hundimiento, donde la intervención de un buen amigo puede obrar maravillas. Por eso, para la depresión que no sea biológica ni fisiológica, es bueno que los alumnos conozcan por ejemplo la terapia cognitiva de Beck (BECK, A., 2007), con sus tres momentos: 1) identificar el pensamiento que desencadena la depresión; 2) rechazar ese pensamiento sin discutirlo, durante al menos una semana; 3) cambiar ese pensamiento negativo (nadie me quiere, todo lo hago mal, los demás triunfan y yo no), cada vez que se presenta, por el pensamiento positivo contrario (mis padres y mi novio o novia me quieren, hago muy bien la paella o nado muy bien o saqué buenas notas en los estudios, tengo éxito con las chicas o en el fútbol o en el dibujo o en que todos me consideran responsable). Al final, se crea un automatismo eficaz, por el cual todos los pensamientos que empezaron mal terminan convertidos en pensamientos estimulantes. 


\section{Esperanza}

Los alumnos deberán saber definir, con sus propias palabras y con toda claridad, en qué consiste la esperanza; qué es ilusión; que el optimismo no es ver la botella medio llena, sino interpretar las dificultades y fracasos como señal de que hay que esforzarse más, como enseña SELIGMAN, y que sepan que sorpresa puede ser tanto por un acontecimiento agradable como por uno desagradable.

Que definan igualmente sus contrarios: decepción desesperación, desengaño y pesimismo, que como enseña SELIGMAN, es tirar la toalla ante dificultades vencibles.

\section{Miedo y vergüenza}

Los alumnos deberán aprender a definir bien el miedo, la vergüenza, el temor, el terror, el pánico, las fobias, la culpabilidad, la ansiedad y la angustia.

Y sus contrarios: valentía, audacia, temeridad, descaro.

Después se puede discutir con ellos si el miedo y la vergüenza pueden ser útiles, o si es mejor no tenerlos nunca.

También hay que hacerles comprender que la culpabilidad, como proceso íntimo de autodestrucción, siempre es dañina y debe ser siempre reemplazada por la responsabilidad.

\section{Deseo}

Los alumnos deberán llegar a ser capaces de definir bien el deseo, la motivación (tan importante, no sólo para los estudios y para cualquier trabajo, sino también para el juego y los deportes), así como el interés y el capricho.

Y sus contrarios: desgana, aburrimiento y asco.

Sería bueno plantearse con los alumnos esta pregunta clásica: ¿Por qué los niños nacen motivados y se desmotivan en la escuela? Cuando pequeños quieren saber el "por qué" de todo y poco a poco, en el sistema escolar, se aburren y "pasan" de todo. Hay dos teorías fundamentales para explicar esto: la primera dice que lo que desmotiva son los exámenes; tener que examinarse de determinada materia, 
le quita el atractivo, aunque sea la obra de teatro o la novela más interesante. La segunda teoría dice que lo que desmotiva es que damos las respuestas antes de que ellos se hagan las preguntas; usan el ejemplo de un turista que nos preguntara por el número del autobús para ir a un lugar concreto y el lugar de la parada de dicho autobús; ese turista no quiere que le demos información acerca de todos los autobuses que van a todas partes, porque se desconcierta. Eso, dicen, pasa en el sistema escolar. Discutir las dos teorías con los alumnos puede ser muy útil.

\section{Envidia y celos}

Los alumnos deben saber definirlos y comprender por qué son considerados como negativos y ambos son generalmente despreciados.

Deben comprender igualmente que hay una envidia sana, que consiste en desear algo que tienen otros, pero sin querer que ellos lo pierdan y una envidia maligna, que desea que los otros pierdan ese dinero, ese amor o esa salud que tienen.

Sobre los celos, que no sólo se dan en la pareja, sino también entre hermanos y amigos y en el trabajo, será muy útil una discusión sobre si son simplemente un amor exagerado o un complejo de inferioridad posesivo.

\section{Ira y rencor}

Hay que saber definir bien la ira, el enfado, el rencor, la rabia y la impaciencia.

Sobre la ira, una de las emociones más violentas y más peligrosas, conviene discutir con los alumnos la efectividad de las técnicas caseras para controlarla: contar hasta diez, alejarse de la persona o situación que nos produce la ira, ejercicio físico moderado (una buena caminata, nadar con calma), no dejar que la ira llegue a su cumbre sino desactivarla lo antes posible.

También es necesario que los alumnos reflexionen juntos sobre qué hacer cuando es otro el que está airado contra nosotros, cómo calmarlo.

\section{Orgullo}

No todo orgullo es malo, despectivo, altanero. Puede haber un orgullo sano (por las buenas notas en los exámenes, por lo guapos que son los hijos, por un éxito 
deportivo o musical) y uno maligno, con desprecio hacia demás, a quienes se considera inferiores.

También hay que saber bien qué es soberbia y arrogancia.

Y sus contrarios: humildad y sencillez.

\section{8. "Amor que mueve el sol y las estrellas"}

(La frase está tomada de Dante, no de Goleman). El amor es seguramente la emoción más profunda, más noble, más indefinible, más manoseada en canciones y cine, más atractiva para los adolescentes.

Hay que enseñarles a distinguir los tres prototipos de amor: el de familia, el enamoramiento de pareja y la amistad entre amigos.

Según Ortega y Gassety según Erich Fromm los elementos indispensables del amor, aunque no sean los únicos, son: un interés especial por la otra persona, buscar un conocimiento creciente de ella, sentir claramente responsabilidad respecto a ella (deseo de hacerla cada vez mejor) y respeto. Los contrarios de esas cuatro cualidades, tan llenas de riqueza, son: indiferencia, ignorancia, irresponsabilidad, manipulación.

Será muy útil discutir con los alumnos si el amor, en sus tres tipos, desemboca normalmente en un compromiso definitivo y si para que un amor dure debe estar basado necesariamente en amistad.

Igualmente se puede discutir con los alumnos si hay diferencias claras entre amor y atracción sexual o el primero se reduce sólo a la segunda, como enseña el cine.

\section{La tercera oleada fue la educación en valores morales}

Hemos hablado de enseñar a pensar y de cómo conocer, controlar y utilizar con eficacia las emociones. Parece que estos dos factores, lo cognitivo y lo emocional, serían suficientes para educar plenamente a una persona. Pero no lo son. Hemos dicho que si uno piensa bien, pero no controla sus emociones, puede ser violento, cruel o cobarde. Pero ahora añadimos que alguien que piensa bien y además conoce y maneja sus emociones y las ajenas, puede ser un gran delincuente, 
astuto, refinado. Porque le falta la tercera y última parte que es imprescindible si queremos educar "personas": los valores morales. Si estos tres factores se trabajan con constancia y eficacia, tendremos personas; si falta alguno de ellos, podemos estar formando seres inteligentes, pero descontrolados o peligrosos. Vamos, pues, a la última parte de nuestro trabajo como educadores: la educación en valores morales.

\section{I.Ante todo, ¿qué son los Valores?}

Busquemos la mayor claridad en este tema tan hermoso, y a veces tan difícil.

Valor es "lo que vale". Viene de la palabra latina "valere", que significa tener fuerzas, ser poderoso, vigoroso. Vale lo que tiene fuerza, poder de atracción. Por eso dice Nicolai Hartmann en su Ética que lo que es percibido como valor, se convierte en objetivo. Dicho con palabras sencillas: cuando una cosa es valiosa para nosotros, nos esforzamos por conseguirla.

En el fondo, lo que todos queremos es ser felices. Y los valores nos prometen felicidad. Pero la felicidad se puede definir en dos direcciones (a lo largo de la historia unos han insistido más en una dirección y otros en la otra):

$1^{\circ}$ La felicidad consiste en estados afectivos agradables, como la tranquilidad, la relajación, el contento, la serenidad.

$2^{\circ}$ La felicidad consiste en la realización personal, que surge precisamente de vivir según los propios valores, aunque vivir así pueda ser costoso y duro.

Si una persona buscara sólo lo primero, los estados agradables, podría caer en la drogadicción, en la pereza, en preocuparse sólo por los placeres físicos. Si una persona buscara sólo lo segundo, vivir según sus valores continuamente, sería un héroe, y no todos podemos ser héroes. Lo sensato es encontrar un equilibrio entre los dos: saber disfrutar de una copa, de una buena comida, de momentos de ternura, de la playa, pero sin que nada de ello vaya en contra de los propios valores, de los propios ideales. Elegir sólo uno de los dos caminos, es salirse de la realidad, con los peligros que acabamos de apuntar más arriba. 


\section{Lo objetivo y lo subjetivo en los valores}

Algunos piensan que los valores son realidades aparte, como las ideas platónicas o como las joyas o el dinero, que hacen que una persona que los lleve encima sea más valiosa. Otros piensan que los valores son puramente subjetivos y por eso, uno puede ver como valiosos un cuadro o un libro o una película o unas ideas que otro desprecia.

Pero la mejor explicación es que los valores existen en la realidad, aunque no aparte (las joyas sí son una realidad aparte de la persona que las lleva, los valores no), sino que están en las cosas y en las personas. Son objetivos. Pero al mismo tiempo, tienen una parte subjetiva: necesitan un eco, una resonancia en quien los percibe. Unas veces la parte objetiva es la más importante, como pasa con una joya magnífica o con una persona muy bella o muy buena. Otras veces, lo más importante es la parte subjetiva: una foto vieja y amarillenta puede ser muy valiosa para alguien, por la carga afectiva que lleva, al ser una foto de sus padres, de sus hijos, de sus seres queridos ya muertos. La explicación de todo esto es que ese eco que los valores despiertan en nosotros tiene mucho de emocional, no es pura razón. Ortega y Gasset decía que para percibir los valores hace falta una antena especial. Quienes no tienen esa antena para los valores estéticos pueden apreciar más un cuadro vulgar que un cuadro de Velázquez, o una música bacalao más que un concierto de Mozart. Y a quienes no tienen esa antena para los valores morales, que son de los que hablamos en estas páginas, les puede dar lo mismo decir la verdad que mentir y lo mismo ganar dinero trabajando que estafando.

Al ser los valores algo fundamentalmente emocional, no pueden ser transmitidos por un razonamiento frío, ni pueden ser impuestos. Si la transmisión se hace en forma autoritaria, esos valores, o se rechazan, o se hacen rígidos y terminan en fanatismo.

\section{Clasificación de los valores}

El más famoso filósofo de los valores, Max Scheler, clasifica los valores en cuatro categorías: $1^{a}$, los que proporcionan placer; $2^{a}$, los vitales, que son la nobleza de ánimo y la rectitud; $3^{a}$, los valores del espíritu, que son la belleza y la justicia, y $4^{a}$, los valores religiosos, que consisten en lo sagrado como opuesto a lo profano. Los valores morales, de los cuales hablamos en estas páginas, serían los que Max Scheler llama nobleza de ánimo, rectitud y justicia. 
En cambio, Ortega y Gasset prefiere ordenar los valores en seis categorías: en la $1^{a}$ están los económicos, como la calidad, el buen precio, la utilidad, la eficacia: en la $2^{a}$ pone los valores vitales, que son la salud, la energía, la vitalidad, la decisión; en la $3^{a}$ cita los valores intelectuales, como la verdad, lo exacto, lo evidente, lo probable; en la $4^{a}$ categoría están los valores estéticos, que son la belleza, la elegancia, la armonía y la gracia; en la $5^{a}$ coloca los valores religiosos, que para él son lo sagrado, lo divino, lo sobrehumano, lo milagroso; y por último, en la $6^{a}$ menciona los valores morales, que son la bondad, la justicia, la generosidad, el amor, la autenticidad, la fidelidad o lealtad, la solidaridad, el agradecimiento, la responsabilidad, la libertad y la paz. Es una enumeración muy completa y muy práctica.

Pues bien, en estos últimos, en los valores morales, es donde centramos nuestra reflexión en estas páginas. Todos los valores son importantes en la educación, pero los valores morales son los que determinan cómo es una persona. La gama es muy amplia y puede ir desde una persona egoísta o asesina, hasta una persona admirable y ejemplar para todos.

\section{De qué valores hablamos en concreto}

Hablamos de los valores morales que han sido más apreciados en todos los tiempos de la historia humana y en todos los lugares, es decir en todas las culturas. Ese resultado de un paciente trabajo de depuración por parte de la humanidad entera, tiene que ser siempre nuestro referente, para no caer en el relativismo de la moda o del capricho individual. Esos valores universales y permanentes son:

La libertad, contra toda forma de esclavitud y de manipulación. No debemos ser esclavos de nadie, ni dejarnos manipular por la propaganda, comercial o política. Ahora teóricamente no hay esclavitud, pero ino somos todos esclavos del consumismo? Aunque Séneca decía que lo más valioso es aquello que no se puede comprar: el aire, la vida, el amor, es decir lo que no se puede adquirir por dinero. La libertad es un gran valor, pero muchas veces le tenemos miedo, porque preferimos estar dentro del grupo, aunque éste sea un rebaño.

El amor y su forma más noble, la amistad, que consiste en comunicación, enriquecimiento mutuo, encuentro. Si en la pareja sólo hay atracción física y no hay amistad, esa pareja no es estable. El amor es lo contrario al odio, a la envidia y sobre todo a la indiferencia. 
La solidaridad, que es amor al débil que está amenazado en sus derechos o en su dignidad. Está relacionada con la generosidad y con la compasión. Es contraria al egoísmo y a la despreocupación.

El perdón está relacionado con la generosidad y es la capacidad de comprender a quienes nos hayan ofendido y olvidar la ofensa. Puede tener un mérito sobrehumano. Se opone al rencor y al odio.

La fidelidad o lealtad, en la pareja, entre amigos, en el grupo, es lo opuesto a la traición y al olvido.

La responsabilidad es saber cumplir los compromisos que uno ha aceptado. Sin ella no puede haber verdadera libertad, ni se merecen ser libres quienes no sean responsables.

La paz, en la familia, entre grupos, entre naciones. No es sólo la ausencia de conflicto, armado o no, sino respeto mutuo y capacidad de convivir y cooperar con quienes piensan de modo distinto al nuestro. Es lo contrario a la guerra, a las peleas, al conflicto, los enfrentamientos.

La coherencia o autenticidad es la coincidencia entre lo que vivimos, lo que decimos y lo que pensamos. Las tres cosas deben coincidir fielmente y por eso no es tan fácil ser coherentes o auténticos. Es lo contrario a la hipocresía, al fariseísmo.

Por último, la justicia, que consiste en dar a cada uno lo que le pertenece, en dinero, en atención, en educación, en tiempo, en respeto. La justicia es anterior a la compasión. Por su importancia, hay en todos los países y desde el comienzo de la historia humana, organismos encargados de impartir justicia, pero muchas veces han sido y son injustos. La justicia es la base de todos los otros valores morales: sin ella ningún valor tiene sentido. Y es innegable que la situación actual del mundo, con gigantescas diferencias entre ricos y pobres, no es justa. Olvidarse de esto y no hacer lo que está en las manos de cada uno para remediarlo, ya es una injusticia.

\section{Jerarquía de valores}

Pero iojo!, NO todos esos valores tienen la misma importancia, el mismo peso; por ejemplo, la fidelidad a una persona o a un colectivo no se puede poner por encima de la justicia y dar la razón a quien no la tiene, sólo porque es mi pariente o mi 
amigo. O el perdón a los opresores no nos puede llevar a olvidar la solidaridad con los oprimidos.

Tampoco puede uno adherirse fanáticamente a un valor, sin tener en cuenta los demás, como han hecho algunos nacionalistas, que por fidelidad a su tierra, a su lengua, a sus tradiciones y a su cultura, han llegado al asesinato. $O$ como aquellos que están tan obsesionados por la justicia, que son incapaces de perdonar. Decía Nicolai Hartmann en su Ética que la moralidad no consiste sólo en tener en cuenta un valor al actuar, sino en preferir el valor superior al inferior; obra moralmente quien decide siempre lo mejor.

Por tanto, lo maduro, lo auténticamente humano (en el buen sentido de esta palabra), es hacer una síntesis sensata de valores en nuestra vida, una síntesis jerarquizada. Lo vamos a explicar a continuación en estas páginas.

\section{Cómo ayudar a los alumnos a descubrir los valores}

Antes de hablar del mundo de la escuela, hay que aludir necesariamente a la familia. En ella comprobamos que hay quienes tienen hijos sanos moralmente, que van asimilando desde pequeños, sin problemas, los valores que sus padres les muestran con su ejemplo. Y hay quienes tienen hijos difíciles, que no asumen los valores de los padres, porque los hijos son rebeldes o porque los padres no aciertan a trasmitirles esos valores. También hay hijos que no han podido aprender de sus padres, porque esos padres no viven los valores que hemos enumerado antes.

Pero además, antes de llegar a la escuela, tanto los hijos buenos como los rebeldes están sometidos no sólo a los valores familiares, sino también a los que inculca la sociedad, en la calle, en la televisión, en los deportes, en internet. Por supuesto que en la pequeña pantalla aparecen de vez en cuando valores positivos (de los que hemos enumerado antes), en las retrasmisiones deportivas, en los concursos, en las películas. Pero por desgracia, parecen abundar más los que podríamos llamar "valores desmesurados" o "disvalores": el dinero como valor supremo que hay que buscar de forma insaciable, el consumo desaforado como única fuente de felicidad, la búsqueda del placer inmediato, la belleza física como superior a la interior, el éxito rápido y fácil sin esfuerzo.

Una vez llegados los niños a la escuela, nuestra meta en la educación de valores debería ser ayudarlos a descubrir que, si viven los grandes valores citados antes (amor, libertad, generosidad, paz, lealtad, responsabilidad, justicia, compasión, 
perdón), los hayan conocido o no por la educación familiar, serán más felices, más profundamente felices, más durablemente felices, que si tuvieran dinero para comprar todo lo que venden los grandes almacenes y para satisfacer todos sus caprichos.

En la asimilación de valores, en el crecimiento de la conciencia moral, el gran maestro de nuestro tiempo ha sido Lawrence Kohlberg.

Ya el gran Piaget se planteó si el crecimiento moral en los humanos sigue unas pautas comunes, como sucede con el crecimiento corporal y el psicológico. Sus colegas universitarios suizos le respondieron que no, que cada niño evoluciona de modo diferente y en estadios diferentes, en la moral, dependiendo de la enseñanza que hayan recibido de sus padres. Pero Jean Piaget era testarudo y además un trabajador incansable. Empezó a tomar notas del razonamiento moral de niños, jóvenes y adultos y llegó a reunir 23.000 fichas.

Dice Kohlberg que todos los seres humanos, independientemente de su sexo, su raza, su cultura o su religión, crecen en el desarrollo de su conciencia moral a través de seis estadios. Estos estadios, bien conocidos, son:

1. Heteronomía: suele durar los cinco o seis primeros años de vida. No hay conciencia moral, el bien y el mal lo determinan otros. Si no hay quien eduque, se da un período de anomía. Los adultos delincuentes no pasan de este nivel. La actitud educativa básica en este período debe ser mucho cariño y normas claras.

2. Egoísmo mutuo (individualismo): empieza cuando el niño descubre las reglas del juego y también la primera norma moral, la Ley del Talión ("te trato como tú me tratas", para no hablar de ojos y dientes). Hay egoísmo, no delincuencia. Suele durar entre los siete años y el comienzo de la adolescencia, pero muchos adultos se estancan en este estadio y se glorían de estar en él.

3. Expectativas interpersonales: en la adolescencia surge con fuerza el deseo de agradar para ser aceptado. Deseo de entrar en nuevos círculos, de encontrar amor fuera de la familia. Es el tiempo de posibles conflictos entre expectativas de padres (y profesores) y las del grupo de amigos. Suele durar hasta los 17-20 años. No pocos adultos se quedan en él. Se intenta que los otros sean felices, pero queda el egoísmo de ser aceptado.

4. Responsabilidad y compromiso (sistema social y conciencia): el adulto moral se siente responsable de aquello a lo que se ha comprometido. Comienza la 
autonomía. Es un estadio de gran nivel, pero la limitación que tiene es que si no hay compromiso, no hay responsabilidad, con lo que esa responsabilidad se limita a familia, trabajo, amigos.

5. Todos tienen derecho (contrato Social): se reconocen de manera práctica, eficaz, los dos grandes derechos humanos, que son la vida y la libertad: se lucha para que todos puedan ejercerlos. Se supera el propio círculo. Es un paso crucial en el desarrollo moral: reconocer la injusticia de la organización actual del mundo, no conformarse con ella, no aceptarla como inevitable.

6. Todos somos iguales o hermanos (principios éticos universales): se reconoce en la práctica la igualdad y dignidad de todos. La regla que rige este estadio es la "regla de oro": hacer por el otro lo que quiero que hagan por mí. Kohlberg pone como ejemplos a M. L. King, a Gandhi, a la madre Teresa, Pero dice que hay muchas personas, en todas partes del mundo, en todas las familias, que viven esto de verdad.

\section{Métodos para enseñar valores}

Ya que queremos dar un enfoque práctico a este artículo, vamos a detenernos un momento sobre los métodos que pueden servirnos para educar en valores.

El primero es, naturalmente la vida: el ejemplo de padres, profesores y personas admiradas. Y el diálogo con iguales sobre temas morales. Y el conocimiento de las grandes religiones y del pensamiento de los grandes hombres.

Kohlberg propone la discusión de dilemas morales, de modo que en la discusión los iguales se ayuden mutuamente a crecer en los estadios morales señalados.

También puede ser muy útil la dramatización de una película o novela: un grupo prepara la dramatización del final de esa película o novela, tal como la presenta el autor. Otro grupo prepara la dramatización con un final distinto, desde una perspectiva moral distinta. Cuando todos han visto las dos representaciones breves, se discute entre todos: 1) si había otras soluciones posibles, 2) cuál sería la mejor moralmente, 3) qué sentimientos tuvieron durante las representaciones.

El método de clarificación de valores (PASCUAL, A., 1995) pide a los alumnos que descubran cuáles son sus valores reales, los que les mueven en la vida. Luego se 
confrontan esos valores suyos con la experiencia humana de siglos, concretada en los valores que mencionamos más arriba. A continuación, se clarifica cuál es su jerarquía de valores.

De entre otras técnicas posibles recomendamos la de dar a los alumnos frases inacabadas, en las que se plantea un problema moral, para que las completen de forma anónima: Por ejemplo: "veo un accidente en la carretera y yo...", "veo a un amigo mío robando y yo...", "si pudiera vender una fruta averiada a una señora que tiene mala vista, yo...", "me dan de más al darme la vuelta de una compra y yo...", etc. Luego se leen todas las respuestas anónimas y se discuten entre todos.

\section{Reflexiones finales}

Con lo expuesto hasta ahora, debe quedar claro que para una relación humana, asertiva, son indispensables los tres factores educativos mencionados: lo cognitivo, lo emocional, lo moral. Enseñar a pensar, enseñar a conocer y a utilizar las emociones, ayudarles a descubrir los valores morales. Si uno de los factores falta, toda la educación falla. Sólo si han asimilado esos tres factores serán personas asertivas, es decir "eficaces" y "justas", como dijimos al principio de este artículo.

¿Por qué no han dado los resultados esperados muchos programas escolares de convivencia, de solución de conflictos, de mediación, de educación para la paz? Son programas creativos, inteligentes, bien diseñados. Pero el profesorado, las autoridades escolares, los padres y el público están constatando, con desconcierto, que los resultados de esos programas quedan muy lejos de lo que prometían.

Antes de dar un dictamen definitivo sobre la validez o la inutilidad de esos programas, habría que hacer una evaluación rigurosa de cómo se aplicaron: si el responsable de impartir el programa estaba cualificado, si se dieron todas las horas programadas, si el alumnado fue estable a lo largo de las sesiones, si esos alumnos fueron participativos, si se realizaron las actividades programadas o se improvisaron otras distintas. Pero incluso antes de que se haga esa evaluación, me atrevo a presentar una hipótesis radical: los programas no dieron resultado porque los alumnos no estaban capacitados para recibirlos.

Si una institución pública o privada promoviera unos cursos sobre "Cómo aterrizar en medio de una niebla densa", o "Cómo despegar de una pista cubierta 
de hielo", todos entenderían, aunque no se dijese en el anuncio, que esos cursos eran para pilotos. No se inscribiría un panadero, un futbolista o un profesor de Filosofía. Para quien no fuera piloto, el curso sería una actividad inútil y además, casi incomprensible.

Pues bien, sugiero que eso es lo que está pasando con los cursos de convivencia, de mediación, de paz. Para saber convivir en paz, para resolver conflictos con la ayuda de un mediador, lo primero que se necesita es que quienes conviven sepan relacionarse como personas. O dicho más breve y más brutalmente: es necesario que quienes conviven sean personas. Si no lo son, estamos dando cursos de pilotos a panaderos.

Porque tanto la Filosofía como la Psicología, insisten en que, para que un individuo merezca el importante título de "persona", necesita esos tres requisitos: saber pensar, conocer y controlar las emociones, tener asimilados los valores morales básicos. Si una sola de esas condiciones falta, no tenemos una persona, sino un aprendiz de persona, una persona en construcción.

Ya hemos publicado cinco libros para el profesorado y dos para padres, todos ellos con varias ediciones. Hemos publicado artículos en las principales revistas pedagógicas de España. Hemos tenido numerosas entrevistas en radios y televisiones locales y autonómicas. Creo que todos los profesores y todos los padres que quieran conocer este Programa, tienen mucha facilidad para hacerlo. En los libros encontrarán descritos los tres pilares de nuestro "Programa para educar personas": enseñarles a pensar, enseñarles a controlar sus emociones, ayudarles a descubrir los valores morales. Todo ello en forma muy activa y con muchos juegos. Es lo que quedará para el futuro, cuando yo ya no esté.

De nuevo, gracias de corazón. 


\section{Bibliografía}

BECK, A (2007) Terapia cognitiva de la depresión, Bilbao, Desclée de Brouwer.

BeCK, RUSH, SHAW y EMERY (1996) Aprenda a tratar con personas conflictivas, Barcelona, Plaza y Janés.

De Bono, E. (1991) Abre tu mente, Barcelona, Plaza y Janés.

Fischman, Soslomon, Greenspan y Gardner, H. (2004) La Buena Opción, Barcelona, Paidós.

Fromm, E. (1981) El miedo a la libertad, Barcelona, Paidós.

- (1997) El arte de amar, Barcelona, Paidós.

GARDNER, H. (1995) Inteligencias Múltiples, Barcelona, Paidós.

- (2001) La Inteligencia reformulada, Barcelona, Paidós.

GolemaN, D. (1997) Inteligencia Emocional, Barcelona, Kairós, 10ª edic.

- (2006) Inteligencia social, Barcelona, Kairós.

HARTMAN, N. (1926) Ethik.

HERSH, R. (21998) El crecimiento moral. De Piaget a Kohlberg, Madrid, Narcea.

KohlBerg, L. (1981) The Philosophy of Moral Development. Moral Stages and the Idea of Justice, Nueva York, Harper and Row.

- (1984) Psicología del Desarrollo Moral, Bilbao, Desclée de Brouwer.

MaCHAdO, A. (1990) Poesías completas, Proverbios y Cantares XXXIV, Madrid Espasa Calpe.

Ortega y Gasset, J. (1940) Escritos sobre el amor humano, Madrid, Revista de Occidente.

- (1981) El tema de nuestro tiempo, Madrid, Revista de Occidente. 
Pascual, A. (1995) Clarificación de valores y desarrollo humano, Madrid, Narcea.

Ross, R. y FaBIANO, E. (1985) Time to Think: A Cognitive Model of Delinquency Prevention and Offender Rehabilitation, Johnson City, Institute of Social Science and Arts.

Savater, F. (1994) Sobre vivir, Barcelona, Ariel.

SCHeler, M. (1960) El puesto del hombre en el mundo.

Segura, M. (2009) Ser persona y relacionarse, Madrid, Narcea, $6^{a}$ edición.

- (132011) Enseñar a convivir no es tan difícil, Bilbao, Desclée de Brouwer.

Segura, M. y ArCAS, M. ('2007) Educar las emociones y los sentimientos, Madrid, Narcea.

- ('2012) Relacionarnos bien, Madrid, Narcea.

Seligman, M. (1998) Aprenda optimismo, Barcelona, Grijalbo.

- (2011) La Vida que florece, Barcelona, B (ediciones). 